\title{
واقع المثهد اللغوي في فلسطين ومحاولات التهويد والعبرنة
}

\author{
السيد مُحَّة سالمُ \\ كلية اللغات والاتصال- - جامعة السلطان زين العابدين - ماليزيا
}

sayedsalim@unisza.edu.my

\begin{abstract}
ملخص
يتناول هذا البحث الصراع اللغوي بين اللغة العربية واللغة العبرية على أرض فلسطين المحتلة، وعن حال اللغة العربية الذي يدعو للقلق؛ فبرغم أن اللغة العبية هي لغة رسمية ثانية بموجب القانون، إلا أن إسرائيل تعمل على إقصائها من مجالات الحياة المختلفة، وإبدالها باللغة العبرية التي تعدّ أحد ركائز المشروع الصهيوني لضمان بقاء دولتهم المزعومة عن طريق التهويد المبطن الناعم. وجاءت هذه الدراسة لتنبه على ضرورة الحفاظ على اللغة العربية كجزء من الحفاظ على الوجود الفلسطيني، ولمعرفة التاريخ اللغوي للغة العبرية، وتوضيح المشهد اللغوي في فلسطين، كما وتحدد موقع اللغة العربية بين الهجمات الصهيونية الشرسة عليها ومحاولة عبرنتها، كجزء من مخططات الكيان الصهيوني للقضاء على الوجود الفلسطيني. يهدف هذا البحث إلى: 1. التنبيه على أهمية اللغة العربية في الحفاظ على الهوية العربية والذاكرة التاريخية والرواية الفلسطينية. r. تعيين موقع كل من اللغتين العربية والعبرية في التاريخ الفلسطيني القديم. r. توضيح العلاقة بين قيام الكيان الصهيوني وإحياء اللغة العبرية. ع. الوقوف على محاولات تهيد وعبرنة اللغة في الداخل الفلسطيني. واتبع البحث المنهج التاريخي حيث تم استخدامه في المبحث الأول؛ لذكر نبذات تاريخية عن أرض فلسطين، وتاريخ اليهود ولغتهم العبرية، والمنهج الوصفي لجمع المادة العلمية الأساسية للبحث ووصفها وتفسيرها.
\end{abstract}

\section{الكلمات المفتاحية: المشهد اللغوي، عبرنة، تويد}

\begin{abstract}
This research deals with the linguistic conflict between the Arabic language and the Hebrew language in occupied Palestine, and the worrying state of Arabic. Although Arabic is a second official language under the law, Israel is working to remove it from various areas of life and to replace it in Hebrew One of the pillars of the Zionist project to ensure the survival of their state is alleged through the soft padded Judaization. This study is to highlight the need to preserve the Arabic language as part of the preservation of the Palestinian presence, to learn the linguistic history of the Hebrew language, to clarify the linguistic scene in Palestine, and the location of the Arabic language between the fierce Zionist attacks and an attempt to transcribe it as part of the plans of the Zionist entity to eliminate the existence Palestinian conflict. The aim of this research is to: 1. To alert the importance of the Arabic language in preserving the Arab identity and the historical memory and the Palestinian narrative. 2. The location of both Arabic and Hebrew in the old
\end{abstract}


Palestinian history. 3. Clarifying the relationship between the establishment of the Zionist entity and the revival of the Hebrew language. 4. Attempt to Judaize the language of the Palestinian inside. The research followed the historical approach, which was used in the first topic; to mention historical profiles of the land of Palestine, the history of the Jews and their Hebrew language, and the descriptive approach to collecting, describing and interpreting the basic scientific material.

Keywords: The linguistic scene, Hebrewization, Judaization

المقدمة

إن اللغة ليست بجرد وسيلة لقضاء الحاجات والتعبير عن الرغبات، وليست مجرد وسيلة للتواصل الإنساني والبشري وحسب، إنما تتجاوز اللغة مهامها المنوطة بها تلك إلى دور أوسع وأهم بكثير؛ فاللغة هي أهم المكونات والمركبات التي تتكون منها هوية الفرد والجماعة، ولغة الإنسان وهويته وجهان لعملة واحدة، كما وللغة أهمية كبيرة ولا شك في حفظ ذاكرة الأمم والحضارات وتاريخ الشعوب. ولقد أدرك الكيان الصهيوني دور اللغة العببية في حفظ الهوية العربية والإسلامية للفلسطينيين، وأن اللغة العربية هي رمز الوجود الفلسطيني، وهي الوعاء الذي يحفظ الذاكرة التاريخية لهذا الشعب؛ ولذلك حرصت إسرائيل على تويد وعبرنة اللسان الفلسطيني العربي عن طريق إضعاف اللغة العربية وتفتيتها تدريجيا من خلال وسائل علمية وتعليمية وإعلامية، وتفريغ اللغة العربية من مضموفا وإضفاء الطابع اليهودي عليها، والهدف من وراء ذلك إذابة وصهر شخصية وهوية المواطن الفلسطيني في المجتمع اليهودي، فلا يبق له تاريخ ولا هوية ولا حق في المطالبة بأرضه. لهذا وغيره جاء هذا البحث كمحاولة لتوعية أبناء لغة الضاد بالخطر المحدق بألسنة الفلسطينيين، وبالتحديات الكبيرة التي تواجهها اللغة العربية في الداخل الفلسطيني، والدعوة لحماية اللغة العربية كجزء من حماية التاريخ والوجود الفلسطيني، وكجزء من الحفاظ على الهوية العربية والإسلامية.

\section{المبحث الأول: نبذة تاريخية}

يدّعي اليهود كذبًا أنّ فلسطين هي أرضهم التي كتبها الله لهم، وأنّ لهم تاريخا عريقا، وحضارة مزدهرة، وتراثا لا يُنافس مرتبط بهذه الأرض، ولا يَألون جُهدا في إثبات زعمةم المكذوب بطرائق وأساليب شتّ. فاستعانوا باللغة العبرية التي يعتبروها اللغة الأمّ لجميع اللغات الساميّة، لتكون دليلا وبرهانًا على صدق ادعاءاهم المُفتراة، وأوعزوا للعالم أفّا لغة مستقلة متكاملة، وأنّ كل اليهود بتمعهم لغة واحدة هي العبرية؛ كمحاولة لاستمداد القوة منها. وأنّ هذه اللغة تتكلم بها الملائكة، وأن الرب استخدم هذه اللغة في خلق العالم؛ كمحاولة أخرى لإضافة القدسية عليها. ولمّا كان دأُهم المستمر هو تزييف الحقائق، وتحريف التاريخ، وتغييب الوعي، وتضليل العالم؛ كان لابدّ من المرور سريعا على ما مضى من وقائع في الزمن الغابر، وكان لا مناص من تقصي بعض الحقائق التاريخية؛ لوضع النقاط على 
الحروف، ومعرفة الصحيح من الزائف، وتفنيد الأكاذيب، وتحديد موقع اليهود بالنسبة لفلسطين، ومن تُمّ تعيين موقع وحضور اللغة العبرية في التاريخ الفلسطيني قديما وحديثا.

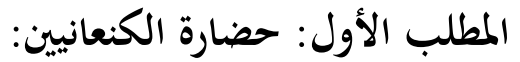

بعد أن رست سفينة نوح -عليه السلام- على شاطيء الجودي، انقسم من آمن معه إلى ثلاثة: القبائل العربية السامية والتي نزلت في شبه الجزيرة العربية، وقبائل الفرس وذهبوا إلى شرق غر الفرات، والأقباط الذين نزلوا مصر (1). وكان لأبناء القبائل العربية السامية لغة واحدة تجمعهم وهي اللغة السامية الأولى، بيد أن تَفَرُّقَ الساميين وانقسامهم إلى قبائل وطوائف متعددة ومختلفة، وهجراتم إلى شتّى بقاع الأرض؛ أدى إلى تفرّعها إلى لهجات، ثم تطورت كل لهجة وزادت مفرداقا حتى غدت لغة مستقلة، لدرجة أنه يصعب الآن تحديد اللغة السامية الأولى لقصورها وقلة مفرداتا، بالإضافة إلى توغلها في القدم، وخلوها من العلم والتفكير (r). هاجرت بعض القبائل العربية من جزيرة العرب إلى بلاد الشام بحثا عن الرزق لصعوبة المعيشة في شبه الجزيرة، فنزحت عدة

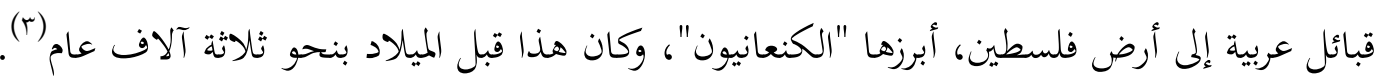
وقد أجمع المؤرخون الشرقيون والغربيون على أن أول آثار معروفة في فلسطين ترجع إلى الكنعانيين، وأن أول

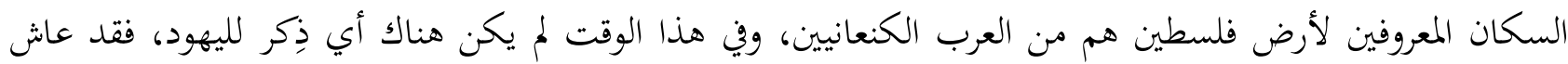

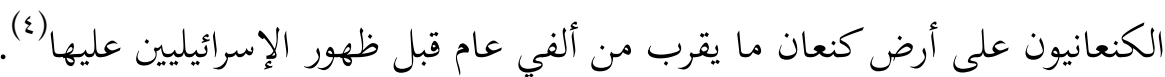
وكانت اللغة المستخدمة على "أرض كنعان" هي اللغة الكنعانية، وهي مشتقة من اللغة السامية الأولى، وقد ضمّت اللغة الكنعانية العديد من اللهجات، منها: العبرية، والتي كانت موجودة على أرض كنعان قبل هجرة الإسرائيليين إليها.

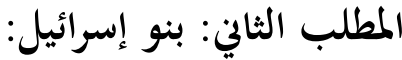

ولمعرفة أصول الإسرائيليين لابد من المرور سريعا على حياة إبراهيم -عليه السلام- وذريته؛ حيث تذكر الروايات أن

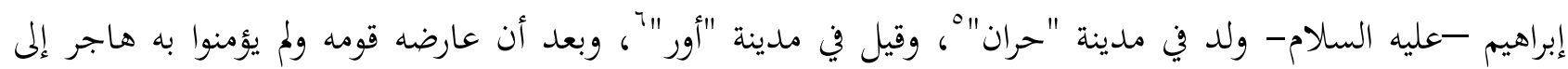
أرض كنعان، ثم إلى مصر، ثم عاد إلى أرض كنعان، وأنجب ولديه إسماعيل وإسحاق -عليهما السلام-.

$$
\text { (1) وثائقي، (تاريخ فلسطين من البداية إلى الآن)، جا، يوتيوب. }
$$

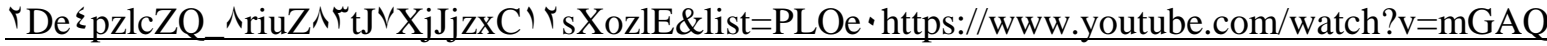
ا(r) انظر : وافي، على عبد الواحد، فقه اللغة، طr، غضة مصر، القاهرة.

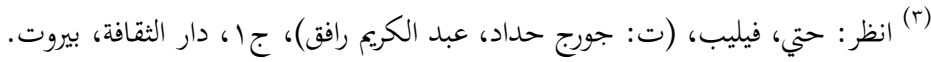

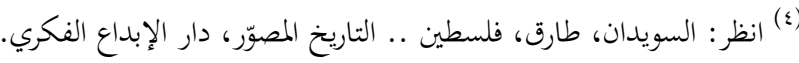

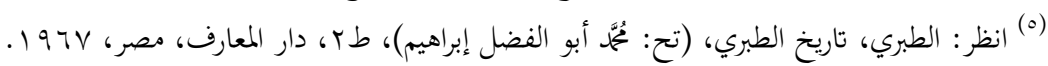


ثم ولد سيدنا يعقوب بن إسحاق على أرض كنعان، لكن أمه أرسلته إلى موطنهم في "حران" عند خاله، ومكث في "حران" ما يقرب من عشرين سنة؛ حيث تزوج ابنتيّ خاله، وأنجب أحد عشر ولدا منهم يوسف -عليه السلام-، ثم عاد إلى أرض الغربة كنعان وأنجب بنيامين (v)، ليصبح أبناؤه اثني عشر ولدا، أتت منهم طوائف بني إسرائيل وهم الأسباط؛

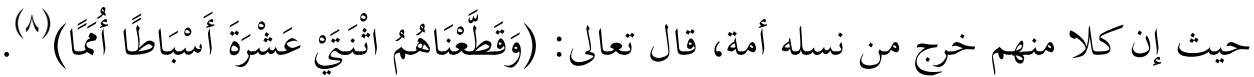
وهذا إن دلّ، فإنما يدل على أن بني إسرائيل عاشوا على أرض كنعان فترات من الزمن، لكنهم كانوا مهاجرين

$$
\text { إليها ودخلاء عليها، فلم تكن فلسطين وطنهم الأصلي بل كانت أرض غربتهم، ومحل هجرقم. }
$$

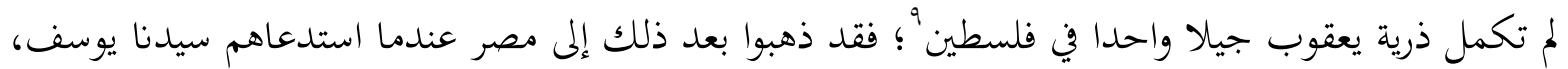

وبقي الإسرائيليون على أرض مصر حتى بعث الله لمم سيدنا موسى، فخرج بهم من مصر لينقذهم من فرعون وشره،

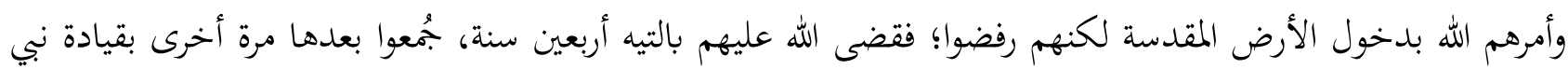

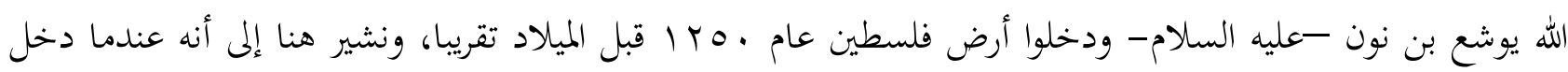
الإسرائيليون أرض فلسطين، كان للكنعانيين حضارة عريقة متكاملة وتراثا مُشيّد، إلا أن الإسرائليين قاموا بسرقة هذه الحضارة وادعوا في التوراة أها لهم، كما أخذوا أيضا الأدب والثقافة والتقاليد الكنعانية ونسبوها إلى أنفسهم، فقد "دلت الحفريات على أن هناك مقارنات ومشابهات من حيث اللغة والأفكار بين الأدب الكنعاني وبين كثير من أسفار

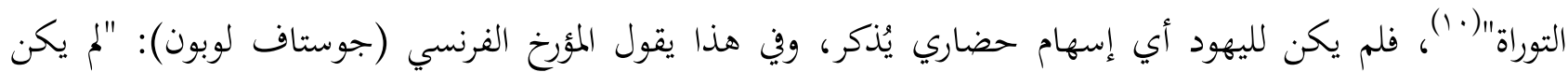

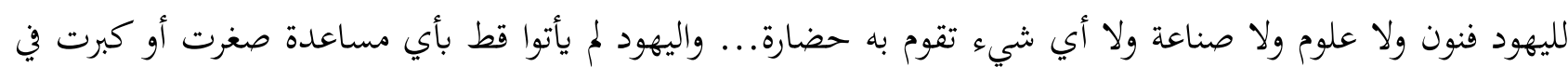

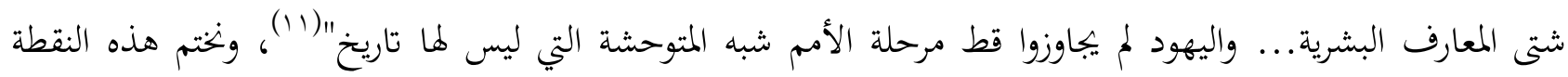
بقول المؤرخ البريطاني (كيث وايتلام): "إن تاريخ إسرائيل القديمة يبدو لحظة قصيرة في التاريخ الفلسطيني القديم" (ז'). ا المطلب الثالث: فلسطين عربية إسلامية:

و"حران" هي مدينة قديمة في بلاد ما بين النهرين تقع حالياً جنوب شرق تركيا.

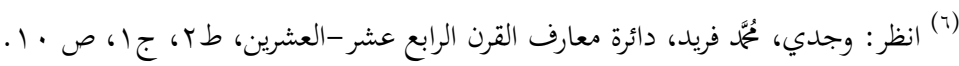

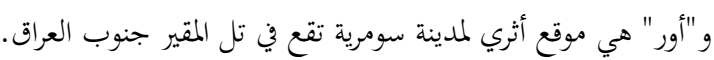

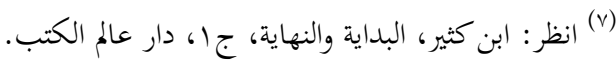

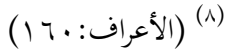

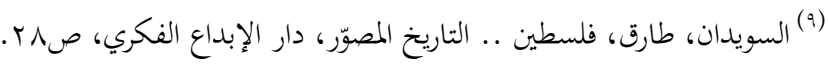

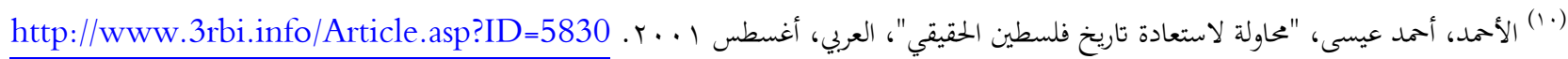

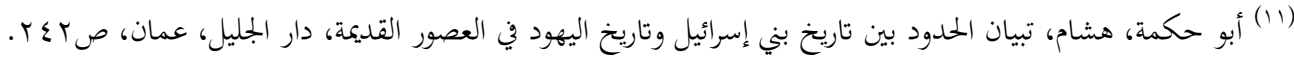

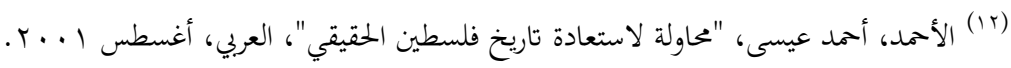


مر على فلسطين طوائف كثيرة؛ فحكمها الآشوريين والبابليين، ثم وقعت تحت حكم الفرس، وظل الكنعانيون وغيرهم من القبائل العربية الأولى على أرضهم، لم يغادروها ولم يهاجروا منها، وتوالت عليها الطوائف، حتى فتحها ودخلها المسلمون

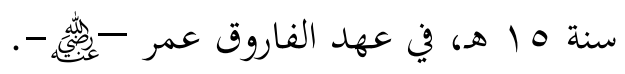
"ويرى ثقات المؤرخين أن معظم أهل فلسطين الحاليين، وخصوصا القرويين، هم من أنسال القبائل الكنعانية والعمورية، ومن القبائل العربية التي استقرت في فلسطين قبل الفتح الإسلامي وبعده؛ حيث اندمج الجميع في نسيج واحد، يجمعهم الإسلام واللغة العربية"(ri). من هذا يتضح أن أرض فلسطين لم تكن يوما أرضا بلا شعب كما يزعم اليهود، بل سكنتها القبائل العربية منذ

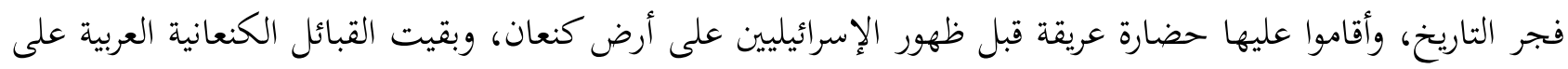
أرض فلسطين حتى دخل الإسلام هذه الأرض، فأسلموا وأصبحت لغتهم عربية، بينما كان اليهود دائمي الشتات والتيه، لم بحمعهم يوما أرض واحدة ولا لغة.

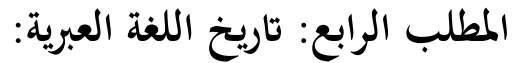

نشأت اللغة العبرية في أرض كنعان قبل هجرة الإسرائيليين إليها؛ حيث كانت مجرد لهجة كنعانية وقتها، وكان الإسرائيليون

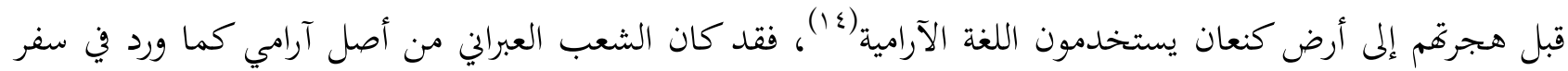
"الثنية".

وعندما هاجر الإسرائيليون إلى أرض كنعان استخدموا اللهجة العبرية، ثم أصيبت هذه اللهجة بكثير من

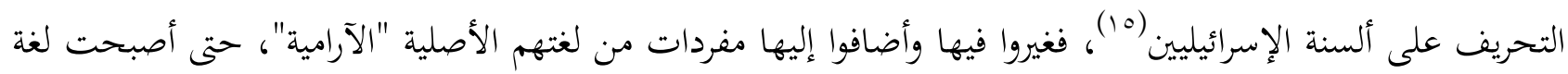
مستقلة خاصة بهم، فاللغة العبرية القديمة إذن هي مزيج من الكنعانية والآرامية. وقد مرت اللغة العبرية بأطوار عديدة؛ حيث قويت في حين، وضعفت في حين، واندثرت في أحيان أخرى، متأثرة في ذلك كله بما يمر به الإسرائيليون من وحدة أو شتات. ولعل أهم الأطوار التي مرت بها اللغة العبرية ما يلي:

\section{- عبرية العهد القديم (العبرية الأولى):}

كما ذكرنا آنفا فإن اللغة العبرية كانت مزيجا من الكنعانية والآرامية، ويقال أيضا أن بعض مفردات اللغات

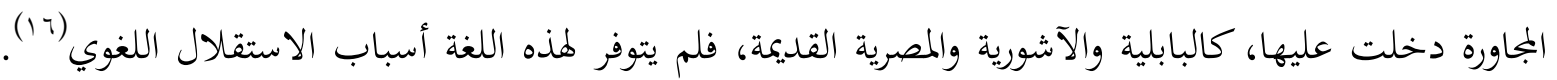

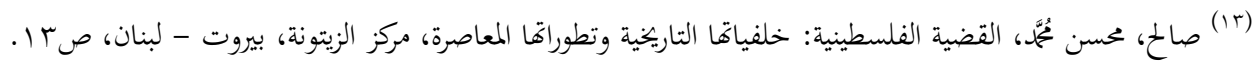

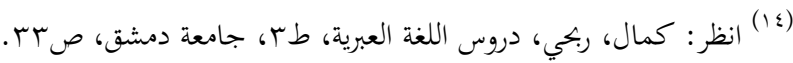

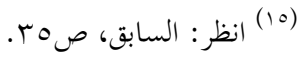

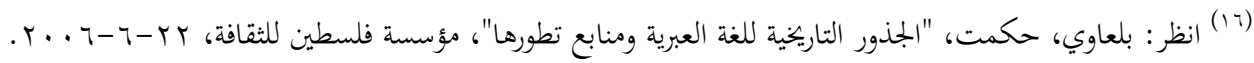


وظلت اللغة العبرية الأولى حية ومستخدمة على ألسنة الإسرائلين منذ دخولم أرض كنعان في القرن الثالث عشر قبل الميلاد حتى القرن الرابع قبل الميلاد، فبعد السبي البابلي لليهود أخذت العبرية الأولى في الاضمحلال شيئا فشيئا، حتى حلت الآرامية محلها على ألسنة اليهود، "وما كاد ينتهي القرن الرابع قبل الميلاد حتى غدت العبرية في عِداد اللغات الميتة في التخاطب"(VV)، وبقيت محفوظة فقط في الأسفار والكتب الدينية، فقد كان أهم ما يميز هذا الطور، أنه وفي القرون الثلاثة الأخيرة من هذه المرحلة دُوّنت معظم أسفار العهد القديم بهذه اللغة، ورغم أن العبرية في هذا الطور تُعد في أزهى عصورها؛ حيث كانت أقرب إلى الصفاء منها في العصور المتقدمة، إلا أها لم تصل إلى أي درجة من درجات الكمال في هذا الطور، فقد بلغت مفردات العبرية الأولى ما بين

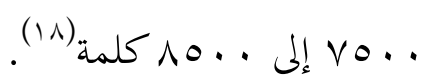

\section{عبرية ما بعد العهد القديم (العبرية الربانية أو التلمودية):} في مطلع العصور الوسطى ظهر ما يسمى بالعبرية الربانية، والتي كان يستخدمها رجال الدين فقط، وكانت العبرية في هذه المرحلة مثأثرة بأسلوب اللغة الآرامية، وتحتوي على الكثير من المفردات الآرامية واللاتينية والإغريقية والفارسية، ولكن الأساس الذي تعتمد عليه ظل عبريا(19). وبهذه اللغة تمت كتابة مجموعة من البحوث في الشئون الدينية من قِبل رجال الدين، وتكونت من هذه البحوث "المشناه"، وتم شرحها باللغة الآرامية فيما أُطلق عليه "الجمارا" -مما يدل على أن اليهود لم يفهموا العبرية الأولى-

$$
\text { ، ومن "المشناه" و "الجمارا" تألّف "التلمود". }
$$

وفي هذا الوقت كان اليهود مفرّقين وموزّعين على كثير من البلدان، واستخدموا لغات البلاد التي نزلوا بها في الحياة الاجتماعية وفي التخاطب؛ حيث ظلت العبرية أيضا في هذا الطور مقتصرة على الكتابات الدينية. -

حاول مفكرو اليهود في القرن التاسع عشر إحياء العبرية الأولى من جديد، لكنهم فشلوا في الموازنة بين العبرية القديمة ومتطلبات العصر الحديث، فاستعانوا بمفردات العبرية التلمودية، ثم استعاروا من اللغات الأوربية كالألمانية والروسية(·) كما تأثرت العبرية الحديثة كثيرا باللغة العربية لشدة الاحتكاك بينهما، وضمت العبرية الحلديثة ما

http://www.thaqafa.org/site/pages/details.aspx?itemid=6601\#.WaqRALpuIqQ كمال، ربحي، دروس اللغة العبرية، طب، جامعة دمشق، صو؟r. (IV)

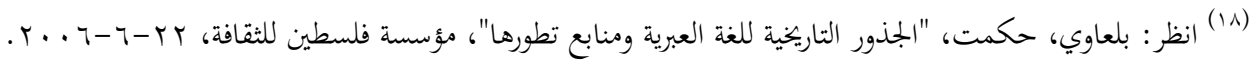

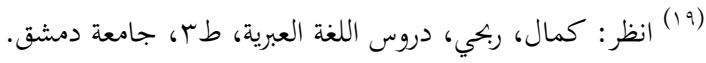

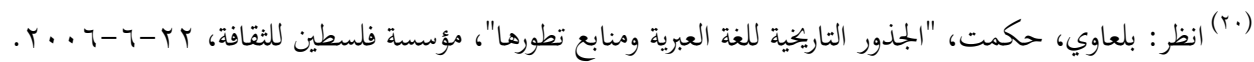




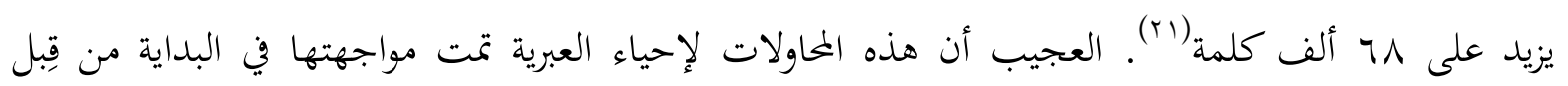
اليهود المتدينين، فقد كانوا يعتبرون أن العبرية لغة مقدسة لا يجوز استخدامها كلغة تخاطب (rr). ولقد بذل رائد إحياء اللغة العبرية اليهودي (اليعازر بيرلمان) جهودا جبارة لنشر العبرية على ألسن اليهود، فقد "كان يؤمن بالترابط الوثيق بين إحياء اللغة العبرية وبتحسد الهوية الوطنية للشعب اليهودي"(rr). حاول اليعازر خلق عبرية حديثة سهلة وبسيطة، ووضع (المعجم العبري القديم) و و(المعجم العبري الحديث)(عاب)، حتى أصبحت اللغة العبرية الحديثة لغة الحديث اليومي، وعادت لغة تخاطب من جديد، بعد مرور أكثر من عشرين قرنا على سباتما، وبسبب كل هذه الإضافات والتعديلات التي أُدخلت عليها، صارت لا تمت بصلة إلى عبرية العهد القديم، لدرجة أن اليهود اليوم لا يستطيعون فهم ما كُتب في التوراة وأسفار العهد القديم والذي كان باللغة العبرية الأولى. الجدير بالذكر أن أكثر من • ب\% من يهود العالم اليوم يعيشون خارج فلسطين، ولا يعرفون شيئا عن العبرية، ويستخدمون لغات البلاد التي يعيشون فيها(ror)، وهذا يبطل زعم اليهود بأفم شعب حضاري بتمعهم لغة واحدة. وعن أصالة أي لغة يقول الدكتور جعفر دك الباب الباحث في علم اللسانيات: "حين نصف لسانًا ما بالأصالة نقصد أنه يتوفر فيه عنصران هما: الإيغال في القدم من ناحية، والاستمرار في الحياة من ناحية أخرى"(جr). ولا نستطيع ألبتة إسقاط الأصالة بهذا المعنى على اللغة العبرية، فإن غضضنا الطرف عن العنصر الأول، واعتبرنا العبرية متوغلة في القدم -ولا يتم ذلك لما أوضحناه سابقا-، فلا يمكن التجاوز عن العنصر الثاني، ولا يجوز بأي حال من الأحوال أن نضفي عليها عنصر الاستمرار، فقد أوضحنا أها كانت لغة حية لمدة عشر قرون تقريبا، ثم أصبحت في عِداد الموتى لأكثر من عشرين قرنا، قبل أن يتم إحياءها من جديد في القرن التاسع عشر، بالإضافة إلى المفارقة الكبيرة بين عبرية العهد القديم والعبرية الحديثة.

$$
\begin{aligned}
& \text { (r) }
\end{aligned}
$$

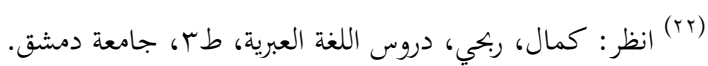

$$
\begin{aligned}
& \text { (rr) } \\
& \text { /https://www.sasapost.com/hebrew-language } \\
& \text { أنظ (r\&) }
\end{aligned}
$$

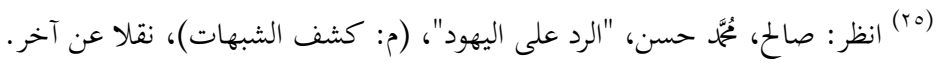

$$
\begin{aligned}
& \text { http://www.khayma.com/kshf/R/Ya/yahood.htm }
\end{aligned}
$$

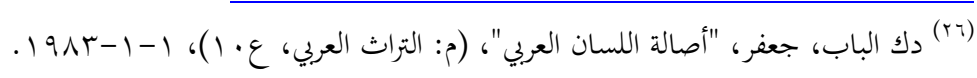
http://archive.sakhrit.co/newPreview.aspx?PID=1931188\&ISSUEID=16102\&AID=361955 
كل ما ذكرناه آنفا، وكثير غيره مما لا تتسع صفحات البحث لطرحه، يبرهن على أن هذه اللغة ليست لغة أصيلة، وليس لها أي حضارة أو تراث تستند عليه، بل هي لغة مسروقة ومرّزة،، ولم يكن لها أي أساس متين تُبنى عليه، وإنما هي مزيج وخليط من لغات شتّى متفرّقة، وأنه حتّى في الفترة التي كانت فيها هذه اللغة أقرب إلى الصفاء، لم تكن أبدا لغة مكتملة وناضجة. فهي إذن لغة مكتوب عليها الشتات والضياع كما كُتب على أصحاها!

\section{المبحث الثاني: واقع الصراع بين العربية والعبرية}

إن الاحتلال من أخطر الأحداث التي يمكن أن تؤثر على اللغة، وقد تعرضت اللغة العربية على امتداد الوطن العربي لهجمة شرسة، وكيد غخطط مدروس، وفي كل مرة كانت تقع فيها دولة عربية تحت وطأة الاحتلال، لم يكن الاحتلال يحارب اللغة العربية نفسها، فاللغة العربية محفوظة ما دامت السماوات والأرض، وإنما يحاول محو اللغة من لسان أصحابها. عندما احتلت فرنسا الجزائر، قال الحاكم الفرنسي في الجزائر: "يجب أن نزيل لغة القرآن العربية من وجودهم، ونقتلع

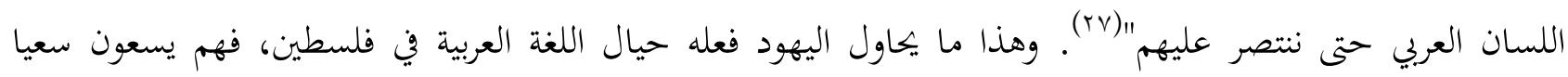
حثيثا لإضعاف اللغة العربية على لسان أصحاها، واقتلاع اللسان العربي واستبداله بالعبري بشتّى الطرق والوسائل، للقضاء على الهوية العربية وهويد لسان أصحاب الأرض، فلا يبق للفلسطيني أي وجود، ولا أي شيء يربطه أو يذكِّره بأصله وهويته.

لقد استطاع الكيان الصهيوني أول قيامه الاستيلاء على أرض فلسطين، والسيطرة على الشعب الفلسطيني سياسيا؛ بيد أنه لم يستطع السيطرة على ذلك الشعب اجتماعيا ولا ثقافيا، لقد عجز الكيان عن خرط وإذابة المواطن الفلسطيني في المجتمع اليهودي، فوجَّه سهامه مباشرة نحو اللغة العربية، إيمانا منه بدور اللغة العربية في الحفاظ على الذاكرة والهوية الفلسطينية. وبالتزامن مع تأسيس الكيان الصهيوني وقيام دولة إسرائيل المزعومة سعت الحكومة الإسرائيلية لفرض فكرة

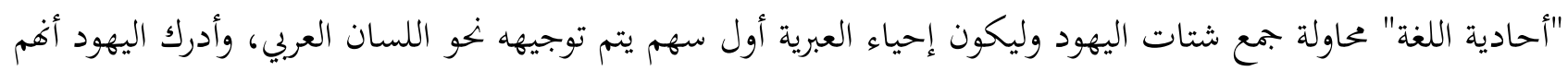


"لا يستطيعون أن يكونوا شعبًا حيَّا إلا بعودةم إلى لغة الآباء، فرفعت الحركة الصهيونية في بداية نشاطها شعار: أرضنا ولغنتنا"(「ᄉ) ويقول (إيلان بابيه) المؤخ الإسرائيلي أن هرتزل وهو يخطط لقيام الدولة الإسرائيلية أراد أن تكون لغتها هي الألمانية لا العبرية، لأن الألمانية لغة التقدم والعبرية لغة بدائية. كما رأى هرتزل أنّ تبنّي لغة عالمية متقدمة كالألمانية سيساهم في القضاء على الانفصال والضياع الذي عانى منه المجتمع اليهودي لقرون. إلا أن اليهود أصروا على اتخاذ العبرية لغة للدولة الجديدة؛ حيث "آمن (إلياعزر بن يهودا) أن إحياء اللغة العبرية

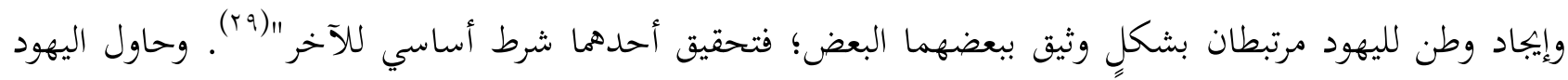
"تعميم تعبير(الدولة العبرية) كاسم يُطلق على الدولة المقامة في فلسطين، لربط تاريخهم بأقدم العصور، ولجعل عصر اليهود

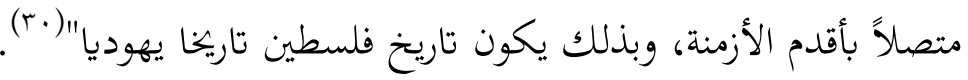
القضية إذن ليست مجرد لغة قوم مكونة من حروف وكلمات تم إحياؤها لتوحيد اليهود وجمعهم، بعد أن كانوا في الشتات يتحدثون بلغات البلاد التي نزلوها، القضية أبعد من ذلك؛ فمسألة إحياء العبرية مسألة لها أبعاد سياسية مرتبطة بقيام الكيان الصهيوني وقيام دولة إسرائيل المزعومة. والقضاء على الهوية العربية، وإضعاف ثقافة ولغة أصحاب الأرض الأصليين عن طريق تصدّر العبرية وهيمنتها

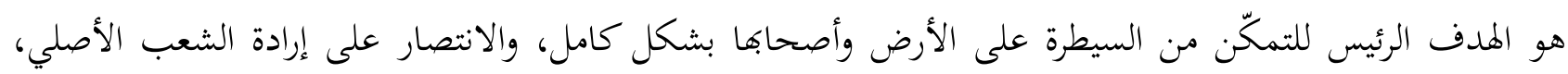
والقضاء على الذاكرة الفلسطينية، ومحو الوجود الفلسطيني، وطمس أي معالم تثبت لأصحاب الأرض حقهم فيها. واليهود إذ يحاربون اللغة العربية بإحياء العبرية، فليس القصد من هذه الحرب تشويه بناء وأصول وقواعد اللغة العربية، لأفم إذا دخلوا في حرب مع اللغة ذاتحا لن يجدوا أنفسهم إلا وقد هُزموا هزيمة نكراء؛ فلا يككن للغة كالعبرية وليدة

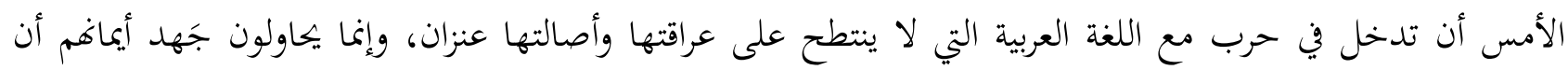
يُفقدوا الفلسطيني هويته عن طريق تقطيع أواصر الصلة بينه وبين لغته العببية التي تحفظ وجوده، وتحفظ لهذه الأرض تاريخها وعروبتها.

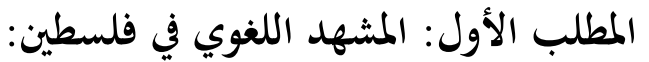

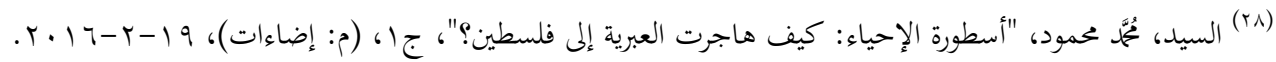
/https://www.ida2at.com/legend-how-the-hebrew-immigrated-to-palestine

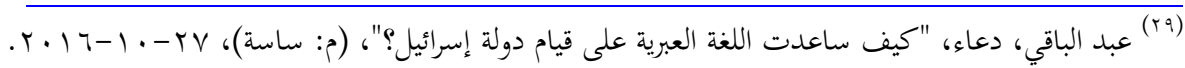

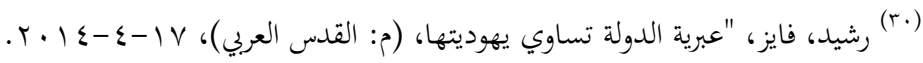
http://www.alquds.co.uk/?p=157197 
إن تعدد اللغات في فلسطين كان شائعا خاصة في المدن الكبرى، ورغم ذلك فإن اللغة العربية كانت اللغة المسيطرة منذ الفتح العربي الإسلامي وحتى نشأة الكيان الصهيوني، إلا أن هناك لغات عديدة أخرى أدت أدوارا هامة في المشهد اللغوي في فترات قليلة من التاريخ الفلسطيني، ففي فترة الحكم العثماني على فلسطين تصدّرت اللغة التركية المشهد اللغوي وكانت اللغة الرسمية للحكومة في فلسطين(اr)، وكان هناك عدد غير قليل من اللغات الأوروبية ذات المكانة الدينية، وقد أقام المبشرون الأوروبيون مدارس في كبريات المدن، مثل بيت للم، القدس، حيفا والناصرة، وعلموا فيها اللغات: الإنجليزية، الإيطالية، الألمانية، الإسبانية والروسية، فأصبح العديد من الناس، -خصوصًا مَن أقام منهم في المدن- ثنائيي اللغة أو متعدّدي اللغة(rr).

عندما احتل الجيش البريطاني فلسطين VI VI كانت اللغة الإنجليزية هي اللغة الرسمية بجانب العبية، كما اعترف الانتداب البريطاني أول قيامه على أرض فلسطين rqT ا باللغة العبرية لغة رسمية بجانب العببية والإنجليزية(r؟) حيث "يحلّد بند r ب لأمر المندوب السامي في فلسطين من العام r 19 وجود ثلاث لغات رسمية في فلسطين/إسرائيل، وهي: الإنجليزية والعربية والعبرية، وما زال هذا المرسوم ساري المفعول إلى يومنا هذا"(عَ)، وعمل الانتداب البريطاني على تعزيز

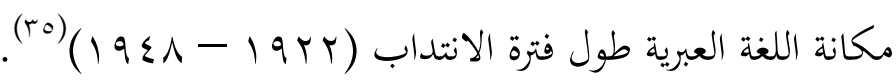
بعد انتهاء الانتداب البريطاني على فلسطين وصدور وثيقة إعلان قيام دولة إسرائيل، أصبح العرب الفلسطينيون أقلية مهمشة، تعيش في صراع مع الأغلبية اليهودية المسيطرة، وبتاهلت حكومة إسرائيل واقع فلسطين المتعدد الثقافات واللغات؛ حيث جعلت اللغة العبرية اللغة الرسمية الأولى للبلاد ثم العربية والإنجليزية على التوالي، "ومن المهم أن نؤكد هنا أن أسبقية اللغة العبرية في إسرائيل لم تأت بمرسوم حكومي، بل نتيجة السياسة الفعلية"(جr). أصبحت اللغة العبرية هي اللغة الأكثر سيادة وحضورا على الساحة؛ فالعبرية هي اللغة الوحيدة في كلّ شأن وقضية في حياة المواطن في إسرائيل، الحيّز العامّ في إسرائيل يتحدث بالعبرية، وهي لغة الجهاز البيروقراطي ولغة التعليم

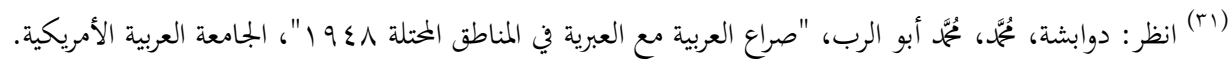

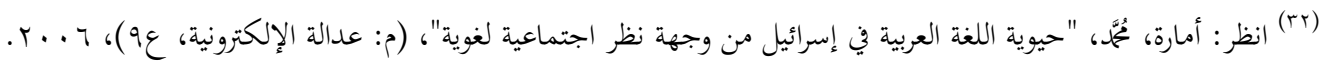

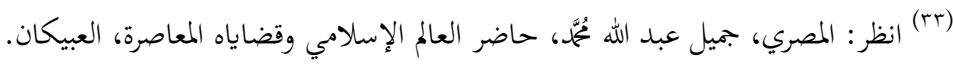

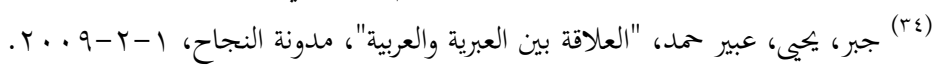
1)http://blogs.najah.edu/staff/yahya-jaber/article/article-

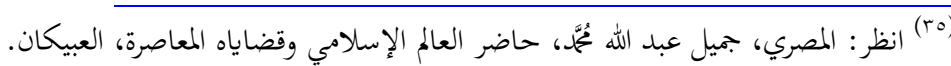

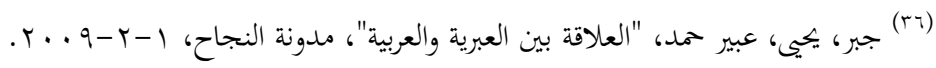


العالي، وهي اللغة الحصرية للإعلام، وهي اللغة السائدة في اللافتات الرسمية والخاصة، وفي الإعلانات الرسمية، والأهم أها لغة أوساط سوق العمل المتاحة للأقلية(rv). وقد بذل الكيان الصهيوني جهودا قوية في ابتحاه عبرنة اللغة لدى اليهود؛ حيث "مارست الحكومات الإسرائيلية الضغط

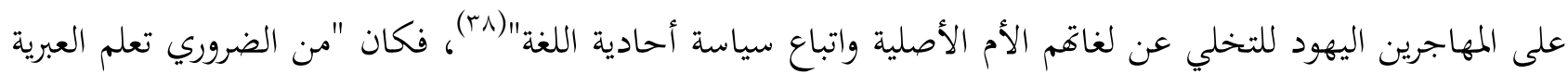

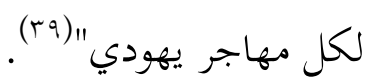
وأصبح اليهود يتحدثون اللغة العبرية خارج منازلم، أما داخل بيوقم وفي أحيائهم السكنية فإفم يتحدثون إما لغة الموطن الذي جاءوا منه، وإما العبرية باللهجة التي يعرفوها، بالإضافة إلى أن آلاف اليهود الشرقيين يتحدثون اللغة العربية،

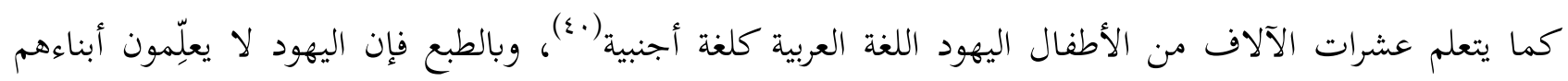
العربية كما هي، وإنما على النحو الذي يريدون.

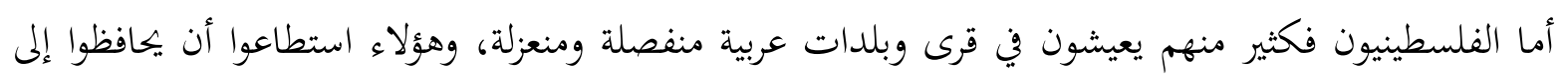
حد ما على لسافم العربي، إلا أنه إذا أراد فلسطيني أن يخرج اليوم من بلدته، فإنه على الغالب "لن يتمكن من إدارة

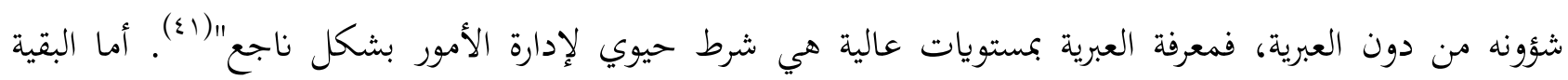
فيعيشون في المدن المختلطة، وبدا من الواضح وجود تاكل بشكل كبير في اللغة العربية على ألسنتهم، بل نستطيع القول

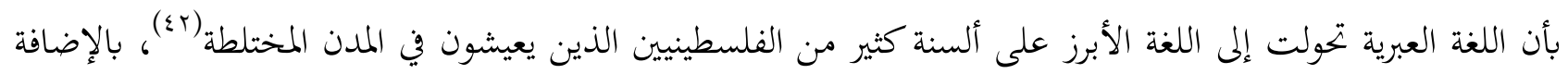

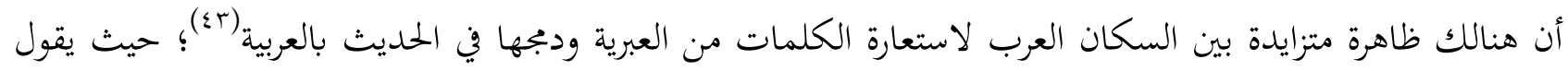
البروفيسور أحمد ناطور في مقالة بعنوان: (بئس الزمان زمانكم): "قد يصل عدد الكلمات بالعبرية في الجملة الواحدة

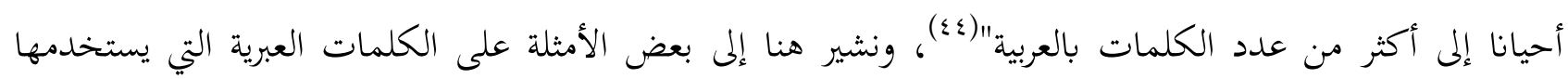
العرب الفلسطينيون ويخلطوها بالعربية: شالوم [שלاه] (سلام)، بوكر توف [داקר טاد] (صباح الخير)، ما شلومخ [מה שלומך] (كيف حالك)، إني متسعتر [אני מצטער] (أنا آسف)، ببكشاه [حבקשה] (من فضلك)،

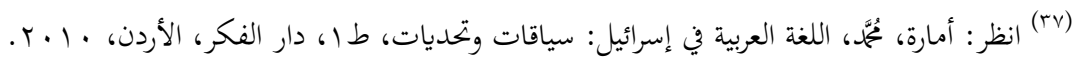

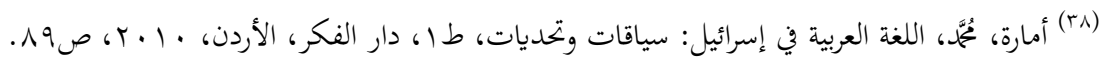

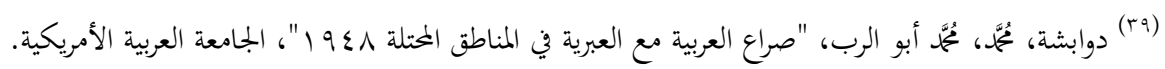

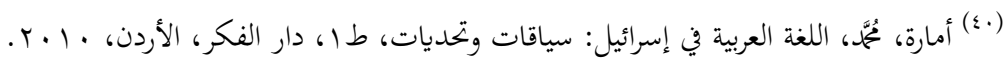

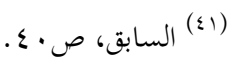

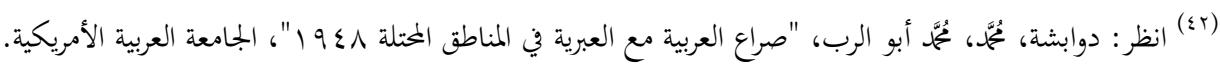

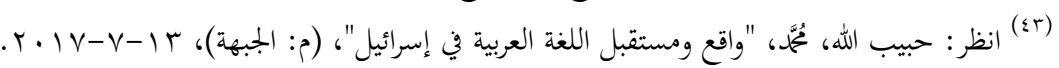

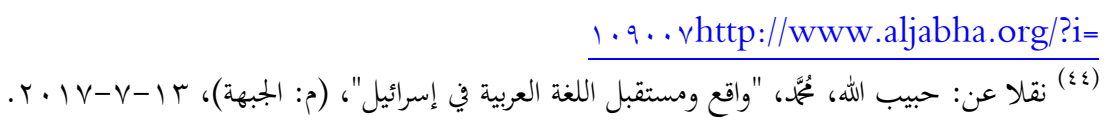


تودا [תודה] (شكرا)، سليحا [0ליחה] (عفوا)، كين [כן] (نعم)، لو [לא] (لا)، رمزور [רמזור] (إشارة ضوئية)، كوبات حوليم [קופת חולים] (معطة تزويد الوقود)، سوكار [مוכר] (سكر)، ميلاح [مוכר] (ملح)، تبوح [תפוח] (تفاح)، افتيح [אבטיח] (بطيخ)، حلاف [חלב] (حليب)، روفيه [רופא] (طبي)، بيت حوليم [בית-חולים] (مستشفى) (s:). خلاصة المشهد أن إسرائيل تعترف قانونيا بالعربية كلغة رسمية ثانية، مما يعني رؤية اللغة العربية حاضرة بجانب العبرية في مجالات الحياة المختلفة، لكن الواقع يبيّن أن ثنائية اللغة ما هي إلا سياسة صورية غير فاعلة؛ فالعبرية هي المسيطرة على المشهد اللغوي. وبوجود الاحتلال لابد من وجود الاتصال بالمحتل، فأصبح العرب الفلسطينيون يتحدثون العبرية في العمل وعند تأدية المصالح الرسمية، ونتيجة لمذا الاتصال تسلَّت الكثير من المفردات العبرية إلى لغة التخاطب المحكية بين العرب، وتراجعت اللغة العربية بشكل كبير وواضح على ألسنة الفلسطينيين وحلت محلها الكثير من المفردات العبرية.

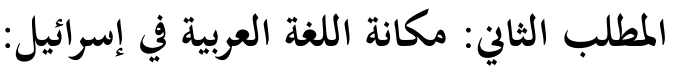

وعند الحديث عن أهمية ومكانة اللغة العربية، فإن البعض يدلل على وجود مكانة لها في المشهد اللغوي في إسرائيل بالمادة r ب من المرسوم الملكي البريطاني التي أشرنا إليها سابقا، مما يوجب أن تجد العربية تتثيلا متساويا مع العبرية في شتى مجالات الحياة الاجتماعية اليومية، لكن العبرة ليست بما سّنه القانون، العبرة بما اتخذه الكيان الصهيوني من سياسة فعلية له؛ فالواقع يقول أن هناك فجوة كبيرة بين ما اعترف به القانون رسميا وبين السياسة الفعلية المنتهجة. إن العبرية هي اللغة الطاغية والمسيطرة في الدولة، في حين أن العربية مهمّة لدى الأقلية الفلسطينية المهمشة

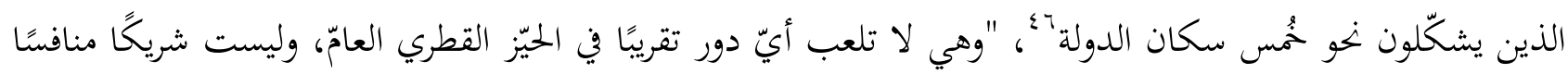
في دولة ثنائية اللغة"(s). وبعد أن كانت اللغة العربية لغة رئيسية أولى لعدة قرون تحولت بين ليلة وضحاها إلى لغة ثانوية مهملة بفعل تغير الظروف السياسية، وأصبحت لغة هامشية لا تكاد تُسمَع لا في المؤسسات الحكومية الرسمية، ولا حتى في المؤسسات المحلية إلا قليلا، لا تُسمَع العربية إلا على ألسنة الأقلية العربية وألسنة اليهود الشرقيين كلغة تخاطب بينهم، وحلت محلها لغة جديدة

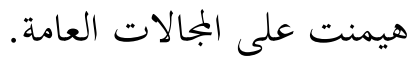

(ن) https://www.paldf.net/forum/showthread.php?t=979131

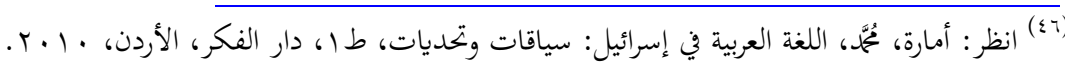

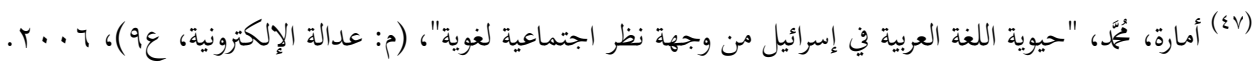


وبرغم تراجع العببية على ألسنة الفلسطينيين كما أوضحنا سابقا إلا أغم يفهمون العببية بوصفها أحد أهم المركبات البارزة في هويتهم الفلسطينية، وذلك وفقا لاستطلاع الآراء الذي وُّزّع على 999 مستطلعا، وقد نظر المستطلعون إلى الجانب الرمزي للغة العربية بوصفه أهم جانب فيها، ويمنحون التدريج الأعلى للتصريحات المرتبطة بالأهمية الرمزية للعربية، مثلا: العربية بوصفها "لغتي الوطنية"، "فخور باللغة العربية"، وهكذا... (مء). • المطلب الثالث: آليات تويد وعبرنة اللغة: يفرض الكيان الصهيوني ضغوطا قوية في اتجاه تويد وعبرنة اللغة على لسان الفلسطينيين، وقد اتبع الكيان عدة آليات تضافرت كلها في أداء الدور المنوط بها، نذكر منها:

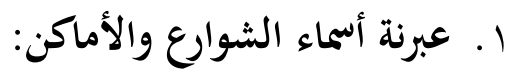

لأسماء الأماكن والشوارع دور هام في حفظ الرواية الفلسطينية والذاكرة التاريخية للأرض، والكيان الصهيوني أدرك

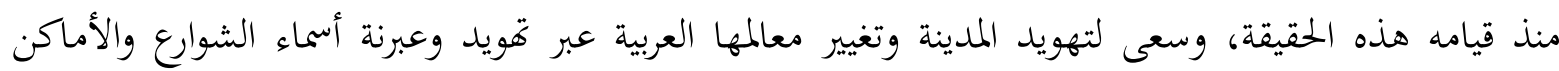
التأكيد على حقه في الأرض، وإثبات الرواية الإسرائيلية.

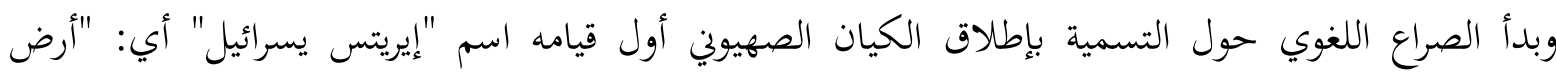

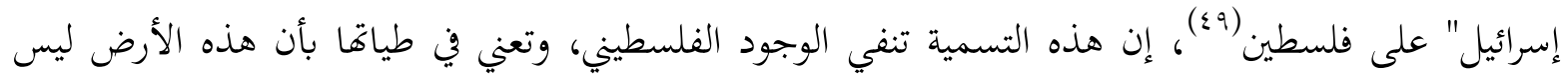

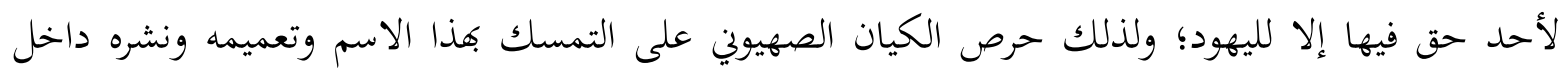

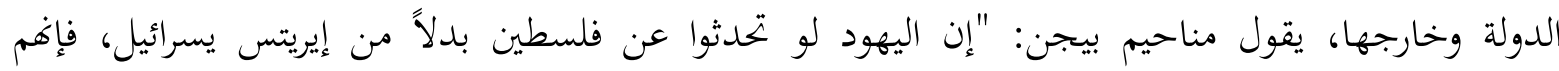

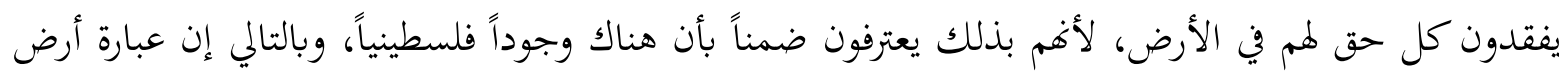

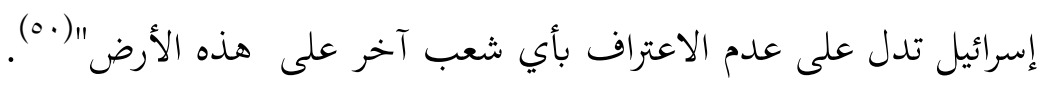

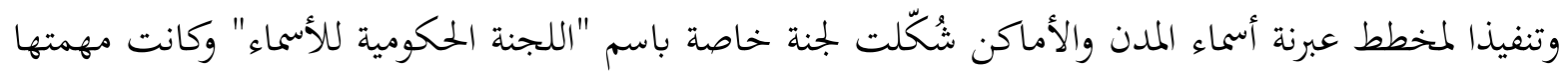

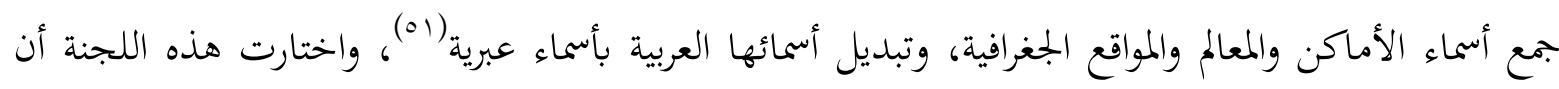

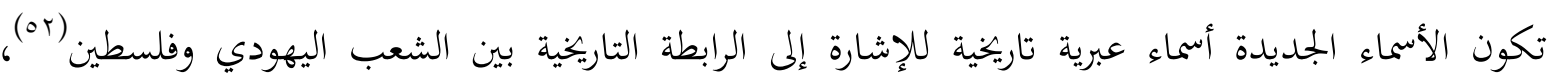

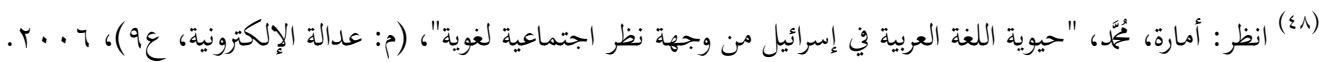

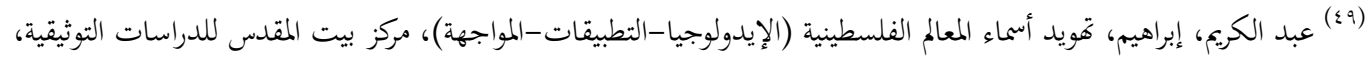
http://www.aqsaonline.org/news.aspx?id=580 r..人-ו r-r . (0.)

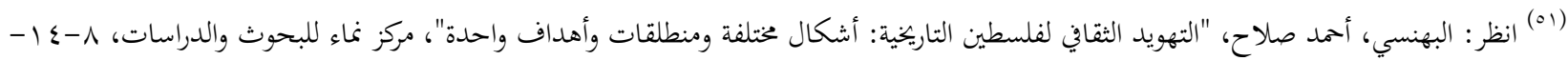
r.00乡http://www.nama-center.com/ActivitieDatials.aspx?id= .r. 10

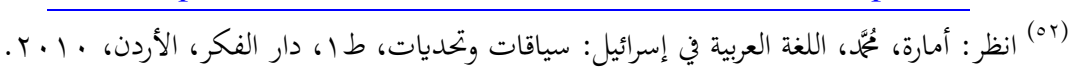


فمثلا: مدينة القدس تمت عبرنتها إلى (يروشلايم)، والخليل تحولت إلى (حبرون)، ونابلس أصبحت (شكيم)،

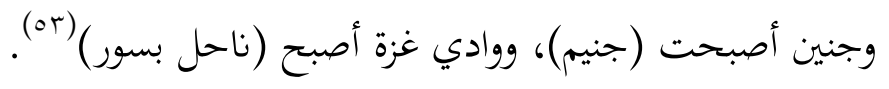

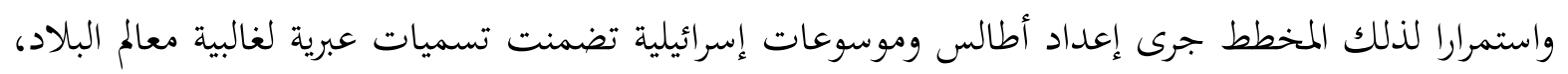

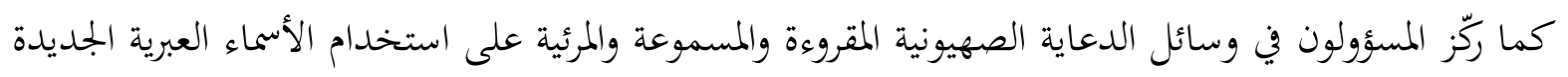

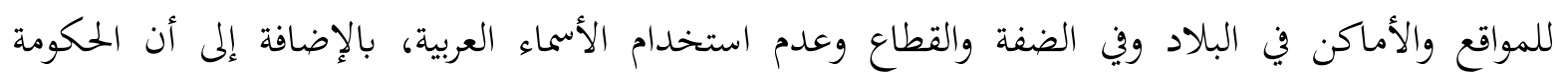

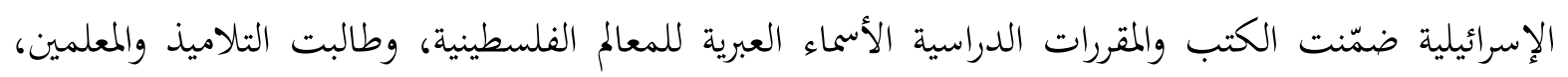
حتى العرب منهم، بعدم استخدام الأسماء العربية لتلك المعالم. وأوضح الباحث سعيد يقين في دراسة بعنوان: (الحركة الصهيونية وخطر التصفية والتزوير الحضاري والتاريخي في

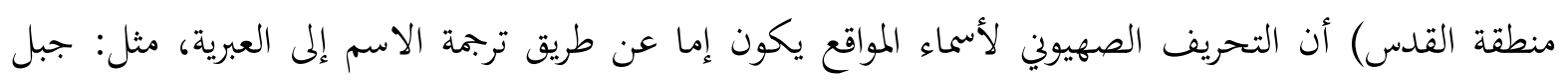

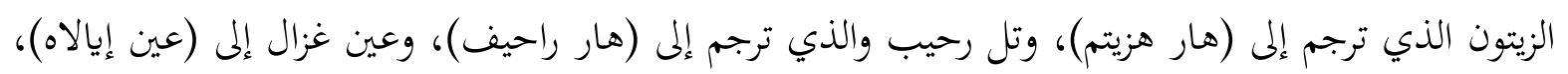

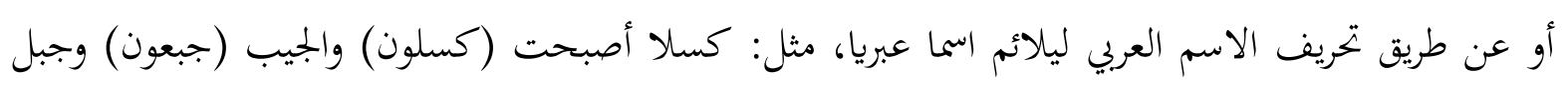

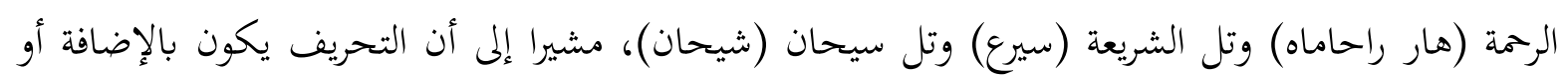

$$
\text { الحذف أو استبدال حرف بآخر (هوان. }
$$

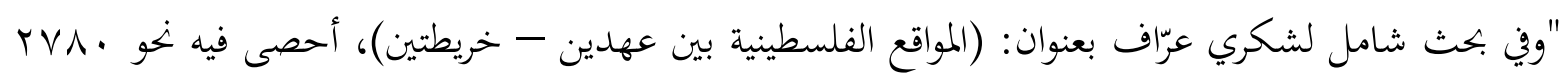

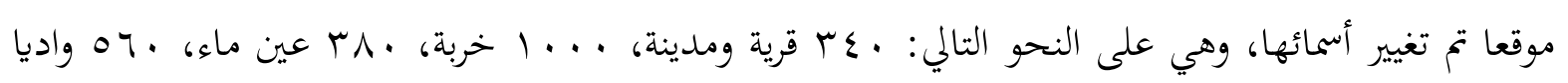

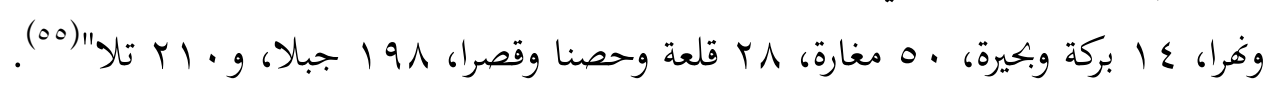

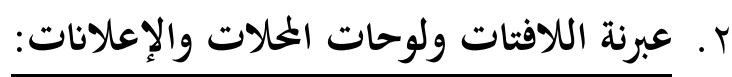

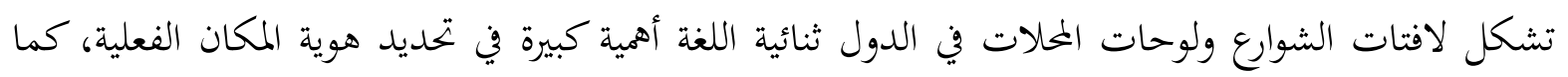

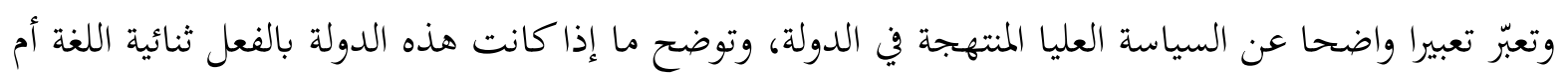
أن هناك لغة مسيطرة على حساب الأخرى.

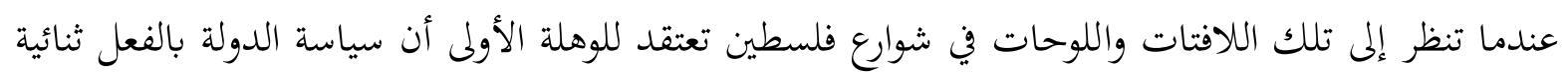

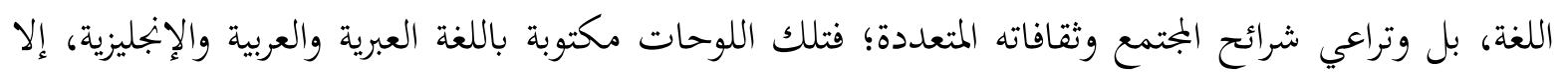

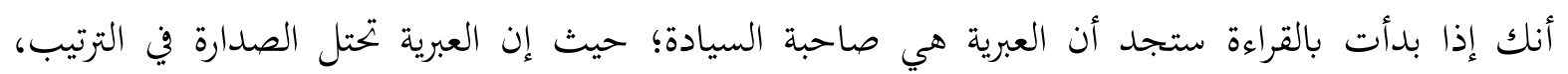

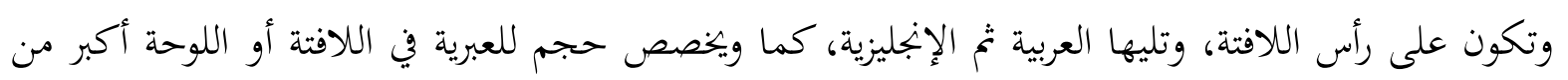

(or) انظر: البهنسي، أحمد صلاح، "التهويد الثقافي لفلسطين التاريخية: أشكال مختلفة ومنطلقات وأهداف واحدة"، مركز نماء للبحوث 
الحيز المخصص للعربية، فحجم الخط العبري تقريبا ضعف حجم الخط العربي، ونتيجة لذلك تظهر العبرية بشكل واضح وجلي على حساب العربية والإنجليزية( جه). بالإضافة إلى أن العربية قد جُردت من مضموها ومخزوها الثقافي والعربي (vo)؛ حيث إن "الكتابة بالعربية لا تكون بكتابة الاسم الأصلي العربي وإنما تكون بكتابة الاسم العبري المرّف، ولكن بحروف عربية، كـ (شخيم) بدلا من

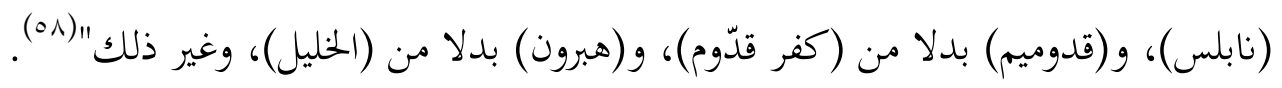

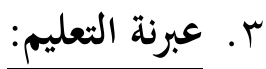

للمدرسة دور فعّال في بناء الفرد وتشكيل شخصيته وهويته، كما أن التعليم هو أحد الميادين الهامة لترسيخ لغة ما، وقد استغل الكيان الصهيوني هذه النقطة في عبرنة ألسنة الأجيال الجديدة الصاعدة. فقررت إسرائيل أول قيامها جعل العبرية لغة التدريس في المدارس العربية، إلا أن القرار قوبل بالمعارضة من العرب ومن بعض اليهود، وفي النهاية تم التوصل إلى إبقاء اللغة العربية لغة التدريس وجعل العبرية مادة إلزامية كلغة ثانية

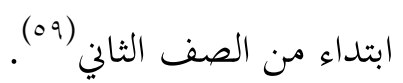
والمناهج التي تم وضعها لتعليم اللغة العبرية تعكس الأهداف السياسية المتبّعة من قبل الحكومة الإسرائيلية في عبرنة التعليم واللغة؛ حيث تركّز المناهج على ترسيخ ثقافة الشعب اليهودي وعاداته وقيمه في الماضي والحاضر، وتعزيز مكانة اللغة العبرية، وزرع الولاء للدولة اليهودية بين الأقلية العربية، واستخدام العبرية كأداة للتواصل الاجتماعي بهدف دمج الطلاب في دولة إسرائيل الزعومة وتأهيلهم للدراسة في الجامعة؛ حيث إن لغة التعليم العالي هي اللغة العبرية(.7). كل هذا وكثير غيره -مما لا تتسع صفحات البحث لذكره- من صور وآليات عبرنة اللغة، يبرهن على أن اليهود لم ولن يكلّوا حتى يعبرنوا لسان الفلسطيني؛ فيسلخونه من جلده وينسونه هويته وأصله وتاريخ أرضه!

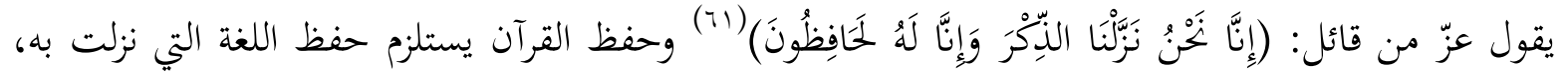
فاللغة التي شَرُفت وعَظُم قدرها بنزول القرآن هي لغة محفوظة بحفظه وباقية ببقائه ودائمة بدوامه -لا شك ولا ريب-!

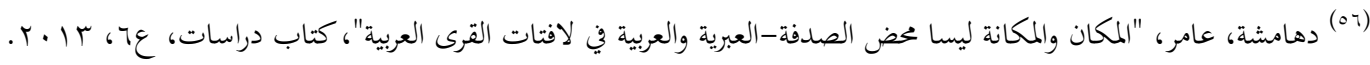

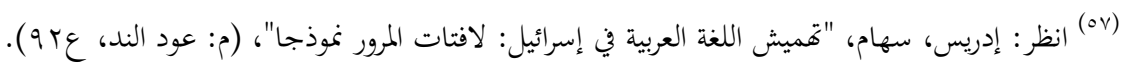
1. 1 vhttp://www.oudnad.net/spip.php?article

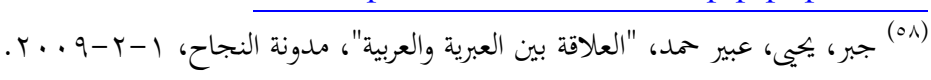

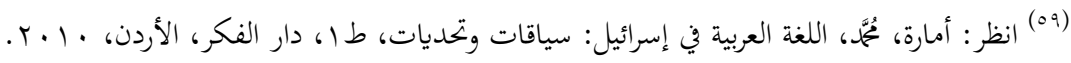

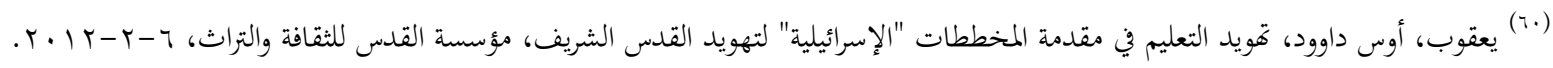
rq) §http://www.alqudslana.org/index.php?action=article\&id= 
وكما يُقال فإنّ الحقّ ما شهدت به الأعداء؛ حيث يقول المستشرق الأمريكي (كوتهل): "إن للغة العربية من اللين والمرونة ما يمكّناها من التكيّف وفق مقتضيات العصر، وهي لم تتقهقر فيما مضى أمام أي لغة أخرى من اللغات

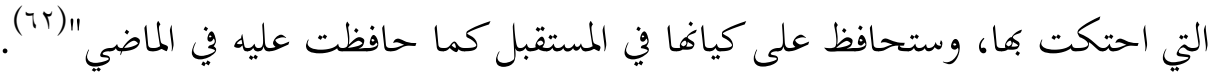
فليس الخوف إذن على اللغة العربية، وإنما الخوف على متحدثيها من أبناء الشعب الفلسطيني من الانجراف والانسياق وراء محاولات العبرنة والتهويد اللغوي التي يمارسها الكيان الصهيوني ضدهم. من هنا غيب بأبناء هذه اللغة السامية ووسائل الإعلام العبية العمل على التوعية بالخطر الذي يهدد اللسان العربي في فلسطين، والتأكيد على دور اللغة في الحفاظ على الهوية الفلسطينية، ورفع الكفاءة اللغوية لدى الفلسطينيين، والحث على تطبيق المبادئ اللغوية السليمة، ومناشدة السلطات المحلية التعامل مع العاملين عليها وعملائها، ومع الهيئات الرسمية المختلفة باللغة العربية؛ لتنتصر إرادة الشعب الفلسطيني، وتعود اللغة العربية بحق كما قال الشاعر عدنان النحوي (rr)

\section{نبعُ يفيضُ على الدّنيا فيملؤهها ** رَيَّا وَيُطلقُ مِنْ أحواضِهِ الحَفَلا}

\section{نتائج البحث:}

ح اللغة العربية هي رمز الوجود الفلسطيني، وهي الوعاء الذي يحفظ الذاكرة التاريخية لمذا الشعب.

$$
\text { ل القبائل العربية هي أول من سكنت فلسطين منذ فجر التاريخ. }
$$

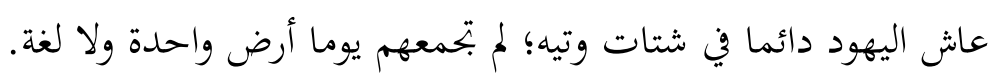
اللغة العبرية ليست لغة أصيلة، وليس لها أي حضارة أو تراث تستند عليه. اللغة العبرية ليست لغة خالصة، بل هي مزيج وخليط من لغات شتّى متفرقة. إحياء اللغة العبرية مسألة لما أبعاد سياسية مرتبطة بقيام الكيان الصهيوني وقيام دولة إسرائيل المزعومة. ل العبرية وليدة الأمس لا يمكن لها أن تدخل في حرب مع العربية التي لم تصل لغة أخرى إلى عراقتها وأصالتها. ل الكيان الصهيوني يهدف إلى إفراغ اللغة العربية من مخزوها الثقافي والعربي وإضفاء الطابع اليهودي عليها. $\checkmark$ ل اللغة العربية لغة رسمية ثانية بموجب القانون إلا أها مهمشة في جوانب الحياة المختلفة.

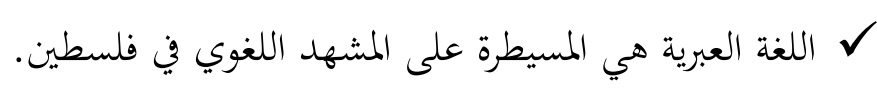


ل اللغة العربية تراجعت بشكل واضح على ألسنة الفلسطينيين خاصة الذين يعيشون في المدن المختلطة. لح اللغة العربية ليس لها مكانة في دولة إسرائيل المزعومة، وهي مهمة لدى الأقلية العربية فقط. لح الشعب الفلسطيني يؤمن بأن اللغة العربية أحد أهم المركبات البارزة في هويتهم الفلسطينية. ل الخوف ليس على اللغة العربية وإنما على متحدثيها من أبناء الشعب الفلسطيني.

\section{المصادر والمراجع}

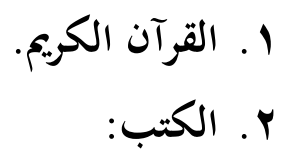

-

- حتي، فيليب، (ت: جورج حداد، عبد الكريم رافق)، جا، دار الثقافة، بيروت. - أبو حكمة، هشام، تبيان الحدود بين تاريخ بني إسرائيل وتاريخ اليهود في العصور القديمة، دار الجليل، عمان. - - السويدان، طارق، فلسطين .. التاريخ المصوّر، دار الإبداع الفكري. - صالح، محسن تُمَّم، القضية الفلسطينية: خلفياتا التاريخية وتطوراتا المعاصرة، مركز الزيتونة، بيروت - لبنان.

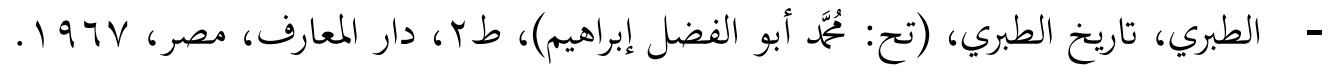
- - ابن كثير، البداية والنهاية، جلا، دار عالم الكتب. - - كمال، ربحي، دروس اللغة العبرية، طب، جامعة دمشق. - المصري، جميل عبد الله مُحَّة، حاضر العالم الإسلامي وقضاياه المعاصرة، العبيكان. - وافي، علي عبد الواحد، فقه اللغة، طس، هضة مصر، القاهرة.

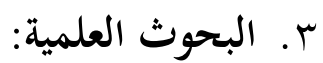

- أمارة، مُحَّ، "حيوية اللغة العربية في إسرائيل من وجهة نظر اجتماعية لغوية"، (م: عدالة الإلكترونية، عج)، .$T \cdot .7$

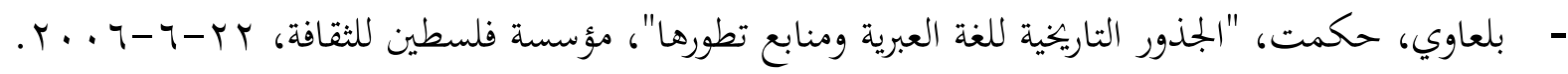

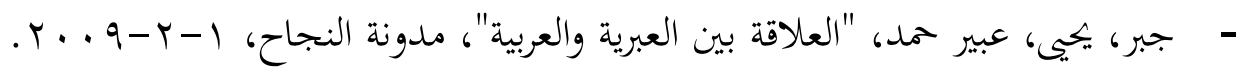
- دهامشة، عامر، "المكان والمكانة ليسا مض الصدفة-العبرية والعربية في لافتات القرى العربية"، كتاب دراسات، .$+1 T \cdot 7 \varepsilon$

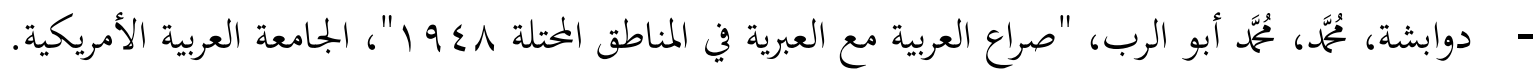


- - الكريم، إبراهيم، تويد أسماء المعالم الفلسطينية (الإيدولوجيا-التطبيقات-المواجهة)، مركز بيت المقدس للدراسات

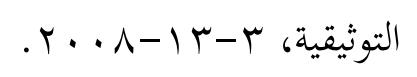

- - البهنسي، أممد صلاح، "التهويد الثقافي لفلسطين التاريخية: أشكال مختلفة ومنطلقات وأهداف واحدة"، مركز

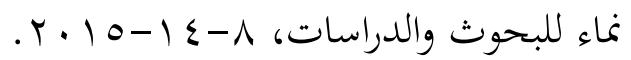

ع ـ المقالات:

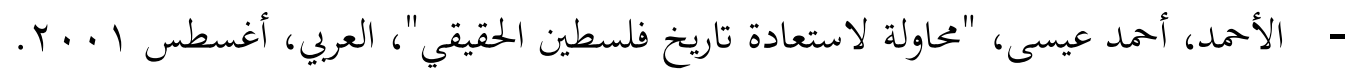

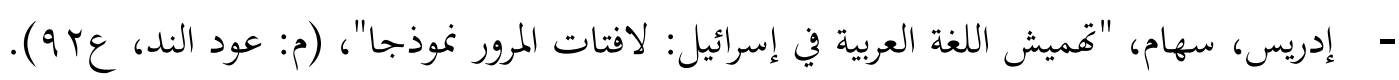

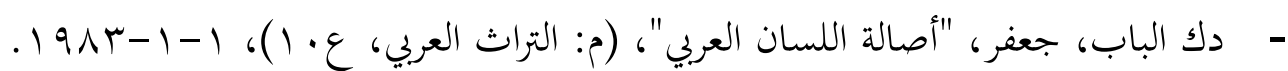

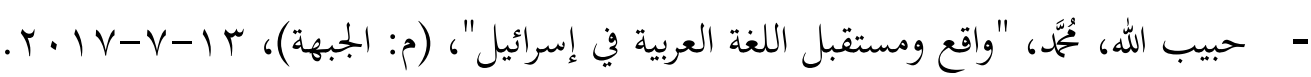

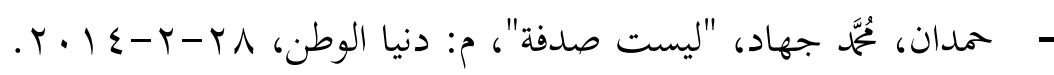

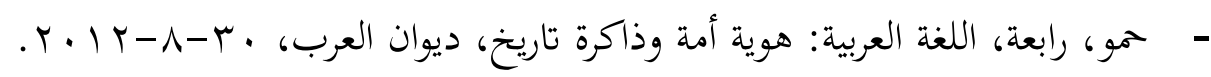

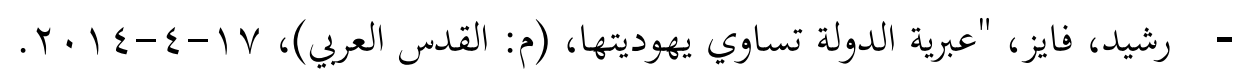

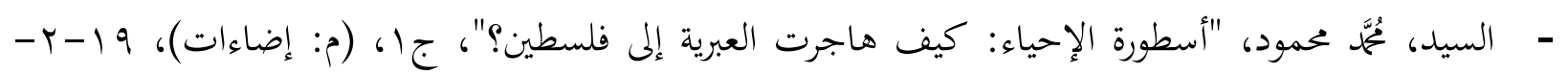
.$T \cdot 17$

- ميعقب، أوس داوود، تهويد التعليم في مقدمة المخططات "الإسرائيلية" لتهويد القدس الشريف، مؤسسة القدس

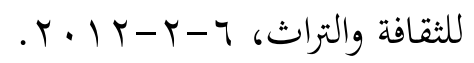

